\title{
MAROLO (Annona Crassiflora Mart.): GERANDO TRABALHO E RENDA
}

Originais recebidos em: 15/03/2010

Aceito para publicação em: 12/07/2011

Flávia Della Lucia Universidade Federal de Alfenas flavia@unifal-mg.edu.br

Luciana Azevedo

Universidade Federal de Alfenas luciana.azevedo@unifal-mg.edu.br

Marcelo Lacerda Rezende

Universidade Federal de Alfenas marcelo.rezende@unifal-mg.edu.br

Marcelo Pólo

Universidade Federal de Alfenas marcelo.polo@unifal-mg.edu.br

Marcelo Rodrigues Martins Emater - MG marcelo.martins@emater.mg.gov.br

\section{Resumo}

O presente artigo tem como objetivo relatar as atividades desenvolvidas e resultados obtidos dos projetos de pesquisa e extensão com o marolo (Annona Crassiflora Mart.), executados pela Universidade Federal de Alfenas (UNIFAL-MG) em parceria com a Empresa de Assistência Técnica e Extensão Rural de Minas Gerais (EMATER-MG) e outras instituições. Para essa finalidade, foram realizadas ações no sentido de verificar a participação da comercialização do marolo na geração de renda e absorção de mão de obra de famílias rurais; levantar as condições de escolha, preparo de frutos e produtos elaborados a partir deles; identificar características sensoriais, físico-químicas e de propriedades funcionais da fruta e seus derivados; capacitar manipuladores e extensionistas multiplicadoras em tecnologias adequadas ao seu processamento artesanal, além de capacitar e conscientizar produtores rurais em relação à preservação e aproveitamento do marolo nas propriedades. Essas atividades permitiram principalmente a sensibilização e mobilização da comunidade e sociedade para os problemas envolvidos com a produção e comercialização da fruta. Além disso, possibilitaram a efetiva transferência de tecnologia e conhecimento entre a comunidade do cerrado, acadêmicos, docentes e EMATER-MG, contribuindo, não somente com a renda e a alimentação de muitas famílias, mas também assegurando 0 desenvolvimento sustentável dessas comunidades, protegendo, assim, o cerrado e seus recursos naturais. Os projetos ainda encontram-se em andamento, tendo sido iniciados em setembro de 2008.

Palavras-chave: Geração de renda. Frutas do cerrado. Comunidades rurais.

\section{MAROLO (Annona crassiflora Mart.): GENERATING LABOR AND RENT}

\begin{abstract}
The present article aims to relate the activities developed and the results obtained, in the research and extension projects on Marolo (Annona crassiflora Mart.), performed by the Universidade Federal de Alfenas (UNIFAL- MG) in association with the Empresa de
\end{abstract}


Assistência Técnica e Extensão Rural de Minas Gerais (EMATER-MG) as well as other institutions. For this purpose, there were actions taken in the sense of checking the participation of the commercialization of marolo in the generation of rent and labor for rural families; surveying the selection conditions, preparation of fruit and derived products, identifying the sensorial, physical, chemical and functional characteristics of the fruit and its derivatives; enabling handlers and multiplier extensors in adequate technologies for its artisanal processing, besides capacitating and bringing awareness to rural producers in relation to the preservation and utilization of marolo on the farms. These activities have enabled mainly the awareness and the mobilization of the community and society towards the problems involving the commercialization of the fruit. Furthermore, they turn possible the effective transfer of knowledge and technology among the savanna community, students, academicians, and EMATER$\mathrm{MG}$, contributing not only to the income and feeding of many families, but also assuring the sustainable development of such populations, protecting the savannas and its natural resources. The projects are still on course, having started in September 2008.

Keywords: Rent generation. Fruit from brazilian savanna. Rural communities.

\section{INTRODUÇÃO}

Apesar do reconhecido valor econômico, alimentar e cultural do marolo, ou araticum (Annona Crassiflora Mart.), essa fruta está inserida em uma área cada vez mais comprometida pelas monoculturas instaladas. Essa espécie é endêmica do bioma cerrado, com distribuição restrita (Minas Gerais e Goiás) a áreas bastante perturbadas pela ação antrópica, o que pode ser exemplificado pela quase extinção de uma de suas três variedades: o marolo vermelho. Além disso, como muitas fruteiras nativas desse bioma, seus frutos ainda são pouco explorados comercialmente, restringindo-se a feiras e estradas, apesar da realidade de consumo crescente (VILAR et al. 2008; ROESLER et al. 2007; ROESLER et al. 2006).

A demanda por essa fruta se deve aos seus atrativos sensoriais, como cor, sabor e aroma peculiares e intensos, o que propicia a elaboração de ingredientes alimentares, além de doces, licores, sorvetes, produtos de panificação, entre outros (OLIVEIRA et al., 2009). Acresce ainda o fato do seu elevado valor nutricional, devido aos níveis de açúcares, proteínas, vitaminas e minerais (VILAS BOAS; SILVA, 2009).

No contexto social, o marolo se destaca por fazer parte da alimentação e cultura das populações do cerrado, apresentando uma identidade especial para essa população. Tal é a sua importância cultural que em Grande Sertão: Veredas ele já era citado por Guimarães Rosa: “O quanto em toda vereda em que se baixava, a gente saudava o buritizal e se bebia estável. 
Assim que a matlotagem desmereceu em acabar, mesmo fome não curtimos, por um bem que se caçou boi. A mais ainda tinha araticum maduro no cerrado" (ROSA, 2006).

Atualmente, existem mais de 58 espécies de frutas nativas do bioma cerrado, conhecidas e utilizadas pela população da região (NOGUEIRA et al., 2005). Entretanto, a utilização do marolo é prejudicada pela organização precária em todo o seu sistema de produção e processamento. São poucos os plantios comerciais da fruta, predominando o extrativismo, com crescente risco para as populações nativas da espécie. Essa colheita é realizada por pequenos produtores rurais, que, sem muitas alternativas, têm na extração do marolo uma importante fonte de renda (POLO et al., 2008).

Configura-se então um dos problemas centrais com o qual se pretendeu trabalhar ao desenvolver os projetos de pesquisa e extensão relacionados ao marolo e relatados no presente trabalho: pequenos produtores rurais, sem alternativas disponíveis para garantir sua subsistência, apóiam-se em uma espécie nativa, que, por sua vez, passa a sofrer maior risco de sobrevivência.

\subsection{Objetivos}

O presente artigo tem como objetivo relatar as atividades desenvolvidas e resultados obtidos dos projetos de pesquisa e extensão ${ }^{1}$ com o marolo, desenvolvidos na Universidade Federal de Alfenas (UNIFAL-MG) em parceria com a Empresa de Assistência Técnica e Extensão Rural de Minas Gerais (EMATER-MG) e outras instituições.

Esses projetos objetivaram a geração de trabalho e renda inicialmente na microrregião de Alfenas, estendendo posteriormente para outras comunidades do estado de Minas Gerais, por meio da orientação do manejo adequado de toda a cadeia produtiva do Marolo e da conscientização dos pequenos agricultores e produtores artesanais sobre a utilização sustentável dos recursos naturais do cerrado. Além disso, tiveram como finalidade a mobilização da comunidade e sociedade por meio de eventos, como o I Simpósio Sul-mineiro do Marolo e Frutos do Cerrado, workshops e dias de campo.

Procurou-se, além do impacto favorável na comercialização e distribuição desse produto com representatividade regional, promover a transferência de tecnologia e

\footnotetext{
${ }^{1}$ Os projetos são: Cadeia produtiva do marolo (Annona crassiflora Mart.): atividades de pesquisa e extensão no sul de Minas Gerais, financiado pela Fundação de Amparo à Pesquisa de Minas Gerais - FAPEMIG, por meio do edital de apoio a projetos de extensão em interface com a pesquisa e Marolo: gerando trabalho e renda, financiado pelo PROEXT.
} 
conhecimento entre as comunidades do cerrado, acadêmicos, docentes e EMATER-MG. As atividades multidisciplinares fomentaram a atuação conjunta entre a UNIFAL-MG, EMATER- MG e Prefeituras Municipais das cidades envolvidas, contribuindo para a implementação de políticas públicas de desenvolvimento humano e inclusão social e articulação de parcerias, possibilitando a continuidade da proposta.

No período de definição das ações e metas a serem desenvolvidas, foram consultados técnicos e comunidade de interesse, buscando assertividade com as necessidades da população. As atividades de pesquisa científica subsidiaram todas as ações de extensão pretendidas, consolidando-as.

Desta forma, as ações e metas dos projetos envolveram:

- Verificar a participação da comercialização do marolo na geração de renda e absorção de mão de obra de famílias rurais.

- Buscar informações sob Annona Crassiflora Mart re os critérios utilizados pela população na escolha do fruto para elaboração dos diversos produtos.

- Levantamento de receituário de produtos elaborados a partir do marolo.

- Análise sensorial e físico-química dos frutos e produtos elaborados a partir deles.

- Identificação das necessidades dos manipuladores, visando às boas práticas de fabricação.

- Elaboração de rótulos para os diferentes produtos levantados.

- Elaboração de material didático-pedagógico e treinamento em Boas Práticas de Fabricação.

- Capacitação da mão de obra em tecnologias adequadas ao processamento artesanal do marolo.

- Capacitação dos produtores em composição de custos dos produtos a serem comercializados.

- Implantação de unidade demonstrativa de viveiro de mudas de marolo.

- Implantação de unidades demonstrativas de plantio do marolo consorciado com café e pastagem.

- Capacitação de pequenos produtores rurais em formas adequadas de cultivo do marolo, consorciado ou não com outras culturas, sem agredir o meio ambiente. 


\subsection{Caracterização e justificativas}

A atividade agropecuária na microrregião de Alfenas, região de início das atividades de extensão é um setor com expressiva participação no Produto Interno Bruto (PIB) local. De acordo com o IBGE (2010a), em alguns desses municípios, a contribuição da agropecuária para o PIB alcança valores acima de 40\%, como em Conceição da Aparecida (50,4\%), Carmo do Rio Claro (46,8\%), Fama (45,3\%) e Divisa Nova (42,9\%). Já o setor de serviços, em todos os municípios, contribui com mais de $40 \%$ do PIB. A indústria tem contribuição expressiva apenas em quatro dos doze municípios: Alfenas $(33,3 \%)$, Machado $(33,0)$, Paraguaçu $(27,9 \%)$ e Serrania (20,8\%). Observa-se ainda que muitas delas são agroindústrias, como laticínios, torrefadoras e produtoras de insumos. Essas comunidades possuem, segundo a Contagem da População de 2007, do IBGE (2010b), 220.129 habitantes. Excetuando os municípios de Alfenas e Machado, que possuem respectivamente 71.628 e 37.567, os demais contam com populações inferiores a 20.000 habitantes. O menor deles, Fama, possui 2.219 habitantes.

A importância da criação de alternativas para o desenvolvimento da microrregião evidencia-se ao se analisar esses dados de população e PIB. De acordo com o IBGE (2010a), em 2002 o município de Machado possuía o maior PIB per capita da região ( $\mathrm{R} \$ 6.833,00$ ), seguido de Alfenas (R\$ 6.370,00). Os demais municípios possuíam valores de PIB per capita entre $\mathrm{R} \$ 3.000,00$ e $\mathrm{R} \$ 4.000,00$. Esse fato é relevante, pois demonstra que a região possuía um PIB per capita equivalente à metade do brasileiro, que era de $\mathrm{R} \$ 7.631,00$ nesse mesmo ano.

Outro aspecto levantado no diagnóstico que fundamentou as atividades desenvolvidas está relacionado ao processamento e à comercialização do marolo. Esse problema pôde ser abordado a partir do levantamento das necessidades dos manipuladores e da aplicação de boas práticas de fabricação, visando a padronização dos produtos elaborados. Essas ações visam à implantação de um controle de qualidade que agregue valor e segurança às preparações artesanais e favoreça maior aceitação dos produtos por parte da população. Pretendeu-se que essa diferenciação fosse demonstrada por informações na rotulagem, a qual atestará a qualidade e vinculará o produto à população de origem e a seus aspectos culturais.

Apesar de a qualidade do produto final ser função direta de sua matéria-prima e processamento, também são necessárias a eficiência técnica e econômica da produção para que se obter o máximo proveniente da agregação de valor dos produtos artesanais. Para isso, o acompanhamento da produção das frutas, da demanda e das exigências do consumidor deve 
ser sistemático. É essencial que toda a cadeia produtiva se organize, em especial, na adoção de práticas recomendadas de produção de mudas, manejo da cultura, colheita, pós-colheita, transporte e distribuição, que contribuem para padrões de qualidade e competitividade dessas frutas.

Além desses aspectos, o marolo também é considerado veículo de inúmeros compostos bioativos com potencial antioxidante. $\mathrm{O}$ melhor entendimento a respeito de suas propriedades funcionais pode favorecer a sua utilização pela população. Permitirá, ainda, a projeção desses produtos para posições ainda ocupadas somente pelas frutas exóticas e produtos com alegação funcional, sendo os últimos intensamente divulgados pela mídia.

\section{MATERIAL E MÉTODOS}

As ações e metas dos projetos foram reunidas em cinco grupos, de acordo com suas características e resultados esperados (Quadro 1). As atividades de tabulação dos dados, reuniões de grupos de trabalho, preparo de material didático, análise sensorial e físicoquímica e capacitação da mão de obra no processamento do marolo ocorreram nas dependências da Unifal-MG. Para isso foram utilizados: sala de reuniões, sala de aula e sala de projetos do Departamento de Nutrição; Laboratório de Técnica Dietética e Composição de Alimentos, Laboratório de Tecnologia de Alimentos e Laboratório de Análise Nutricional e Toxicológica in vivo (LANTIN).

As unidades demonstrativas serão implantadas em propriedades rurais da microrregião, selecionadas pela Emater-MG, de forma a atender os objetivos dos projetos. Os proprietários envolvidos se beneficiarão com as mudas viáveis e com os plantios consorciados.

\begin{tabular}{|l|l|l|}
\hline \multicolumn{2}{|c|}{ Objetivos/ Metas: } & \multicolumn{2}{|c|}{ Resultados esperados: } \\
\hline $\begin{array}{l}\text { Verificar a participação da } \\
\text { comercialização do marolo na geração de } \\
\text { renda e absorção de mão de obra de } \\
\text { famílias rurais. }\end{array}$ & $\begin{array}{l}\text { Gerar conhecimentos que fundamentem as } \\
\text { etapas seguintes do projeto e permitam a } \\
\text { sensibilização de pessoas e instituições para as } \\
\text { demais atividades previstas. }\end{array}$ \\
\hline $\begin{array}{l}\text { Levantar as condições de escolha, preparo } \\
\text { de frutos e produtos elaborados a partir } \\
\text { deles. }\end{array}$ & $\begin{array}{l}\text { Gerar conhecimentos para a capacitação da } \\
\text { população de interesse no processamento do } \\
\text { marolo e desenvolvimento das receitas. }\end{array}$ \\
\hline $\begin{array}{l}\text { Identificação das características } \\
\text { sensoriais, físico-químicas e de }\end{array}$ & $\begin{array}{l}\text { Controle de qualidade e elaboração de } \\
\text { rotulagem dos derivados do marolo. }\end{array}$ \\
\hline
\end{tabular}




\begin{tabular}{|c|c|}
\hline $\begin{array}{l}\text { propriedades funcionais da fruta e seus } \\
\text { derivados. }\end{array}$ & $\begin{array}{l}\text { Adequação dos produtos à legislação vigente e } \\
\text { gerar um diferencial para os produtos de } \\
\text { origem artesanal. }\end{array}$ \\
\hline $\begin{array}{l}\text { Capacitação de manipuladores e } \\
\text { extensionistas multiplicadoras em } \\
\text { tecnologias adequadas ao processamento } \\
\text { artesanal do marolo. }\end{array}$ & $\begin{array}{l}\text { - Capacitação de manipuladores e Técnicas do } \\
\text { Bem Estar Social (BES-EMATER), } \\
\text { envolvendo os temas: } \\
\text { 1. Apresentação e discussão dos resultados de } \\
\text { não conformidade encontrados na aplicação } \\
\text { do check list (fase de levantamento de dados). } \\
\text { 2. Importância da higiene pessoal (corporal, } \\
\text { mãos, uniformes). } \\
\text { 3. Higiene dos alimentos. } \\
\text { 4. Higiene dos utensílios, ambiente e } \\
\text { equipamentos. } \\
\text { 5. Capacitação em Técnicas de Fabricação. } \\
\text { 6. Legislação e rotulagem do produto. }\end{array}$ \\
\hline \begin{tabular}{lllr} 
Capacitação e e & \multicolumn{2}{l}{ conscientização } & de \\
produtores rurais & para & preservação e \\
aproveitamento & do & marolo nas \\
propriedades. & & &
\end{tabular} & $\begin{array}{l}\text { - Produção de mudas para distribuição aos } \\
\text { produtores. } \\
\text { - Aumentar a área de plantio do marolo, } \\
\text { inclusive como cultura em APP (Áreas de } \\
\text { Preservação Permanente), melhorando a renda } \\
\text { das propriedades. } \\
\text { - Reduzir o risco de depredação dos } \\
\text { maroleiros nativos. } \\
\text { - Aumentar as possibilidades de utilização do } \\
\text { marolo nas propriedades rurais, } \\
\text { incrementando o seu plantio. } \\
\text { - Divulgar técnicas de produção de mudas e } \\
\text { benefícios do consórcio com pastagens e café. }\end{array}$ \\
\hline
\end{tabular}

Quadro 1 - Objetivos e metas das atividades desenvolvidas e resultados esperados.

Fonte: Elaborado pelos autores.

Para garantir cumprimento dos objetivos propostos, foram desenvolvidos indicadores de acompanhamento e avaliação, conforme relacionado no Quadro 2.

\begin{tabular}{|l|l|}
\hline \multicolumn{2}{|l|}{ Indicadores de Acompanhamento e Avaliação: } \\
\hline Objetivos/ Metas: & $\begin{array}{l}\text { Indicadores de acompanhamento e } \\
\text { avaliação: }\end{array}$ \\
\hline $\begin{array}{l}\text { Verificar a participação da } \\
\text { comercialização do marolo na geração } \\
\text { de renda e absorção de mão de obra de } \\
\text { famílias rurais. }\end{array}$ & $\begin{array}{l}\text { Volume e qualidade da informação } \\
\text { obtida. }\end{array}$ \\
\hline $\begin{array}{l}\text { Levantar as condições de escolha, } \\
\text { preparo de frutos e produtos elaborados } \\
\text { a partir deles. }\end{array}$ & $\begin{array}{l}\text { 1) Volume e qualidade da informação obtida. } \\
\text { 2) Número de listas de verificação de Boas } \\
\text { Práticas de fabricação nos estabelecimentos }\end{array}$ \\
\hline
\end{tabular}




\begin{tabular}{|c|c|}
\hline & $\begin{array}{l}\text { dos produtores gerados (check list). } \\
\text { 3) Reprodutibilidade dos resultados em } \\
\text { laboratório. } \\
\text { 4) Levantamento das conformidades e } \\
\text { inconformidades dos locais visitados. }\end{array}$ \\
\hline $\begin{array}{l}\text { Identificação das características } \\
\text { sensoriais, físico-químicas da fruta e } \\
\text { seus derivados. }\end{array}$ & $\begin{array}{l}\text { 1) Reprodutibilidade dos resultados em } \\
\text { laboratório. } \\
\text { 2) Dados laboratoriais de controle de qualidade. }\end{array}$ \\
\hline $\begin{array}{lll}\text { Capacitação da mão de obra em } \\
\text { tecnologias } & \text { adequadas } & \text { ao } \\
\text { processamento artesanal do marolo. }\end{array}$ & $\begin{array}{l}\text { 1) Número de participantes e freqüência nas } \\
\text { atividades. } \\
\text { 2) Qualidade das atividades práticas de } \\
\text { capacitação. } \\
\text { 3) Motivação dos treinadores para o trabalho. }\end{array}$ \\
\hline $\begin{array}{l}\text { Capacitação e conscientização de } \\
\text { produtores rurais para a preservação e } \\
\text { aproveitamento do marolo nas } \\
\text { propriedades rurais. }\end{array}$ & $\begin{array}{l}\text { 1) Número de participantes nos dias de campo. } \\
\text { 2) Número de mudas produzidas e distribuídas. } \\
\text { 3) Qualidade das atividades práticas de } \\
\text { capacitação. } \\
\text { 4) Motivação dos treinadores para o trabalho. }\end{array}$ \\
\hline
\end{tabular}

Quadro 2 - Indicadores de acompanhamento e avaliação dos objetivos e metas.

Fonte: Elaborado pelos autores.

A sistemática de acompanhamento e avaliação desses indicadores foi realizada da seguinte forma: o acompanhamento do levantamento dos dados relativos a fatores econômicos e de escolha e utilização do fruto pela população e os resultados obtidos nos questionários foram realizados em reuniões semanais da equipe; o acompanhamento das análises laboratoriais (físico-químicas e sensoriais) também foi realizado em reuniões semanais e com a discussão dos resultados obtidos; nas oficinas de capacitação, a avaliação dos conhecimentos teóricos e práticos foi realizada por meio de questionários, utilizando frases para marcar verdadeiro ou falso, seguido da verificação da porcentagem de acertos. Essa avaliação também foi realizada durante e ao final das atividades práticas, em discussões sobre dificuldades e facilidades na execução do processo.

Por fim, para acompanhamento das atividades de campo, foi realizada uma reunião de avaliação com os responsáveis no momento final do evento, discutindo-se sobre as dificuldades e facilidades na execução do processo.

\section{RESULTADOS E ANÁLISE}

Os dados relativos a fatores econômicos e da escolha e utilização do fruto pela população foram coletados por meio de entrevistas baseadas num questionário 
semiestruturado. Foram entrevistas 70 pessoas, entre produtores, processadores e comerciantes de marolo e seus derivados. Como previsto, essas informações foram utilizadas para fundamentar as demais atividades do projeto.

Para as análises químicas e sensoriais, foram obtidos, na microrregião de Alfenas/MG, frutos, polpa e produtos elaborados a partir do marolo. Essas análises estão sendo realizadas em laboratórios da Unifal-MG. Os resultados demonstraram que a polpa do marolo é fonte principalmente de carboidratos, vitamina $\mathrm{C}$ e carotenóides, além de minerais, tais como potássio, fósforo e magnésio. Para análise sensorial, foram avaliados vários produtos da comunidade, eleitos como característicos daquela região, como licor, doce de leite, polpada e doce em pedaços. Os resultados mostraram que os mesmos produtos obtiveram boa aceitação pelos provadores, situando-se entre os termos hedônicos "gostei moderadamente" e "gostei ligeiramente", sendo que suas composições se aproximam do previsto pela legislação de alimentos e bebidas.

As atividades de capacitação ocorreram nos laboratórios de Técnica Dietética e Composição de Alimentos e de Tecnologia de Alimentos da Unifal-MG. Inicialmente, as receitas foram padronizadas durante um período de seis meses por docentes, discentes e técnicas da EMATER, que atuam da microrregião de Alfenas. Posteriormente, 23 Técnicas da EMATER, de todas as regiões do estado, foram trazidas para os laboratórios da Unifal-MG, para a realização de treinamento com duração de uma semana. Nesse momento, foram acrescentadas as experiências dessas participantes, conhecedoras de suas comunidades rurais, contextualizando a troca efetiva entre treinador e treinado, permitindo, inclusive, adequações no material didático. Em seguida, foram realizadas outras sete oficinas, conduzidas com produtores da região e nos laboratórios da Unifal-MG, durante o I Simpósio Sul-mineiro do Marolo e de Frutos do Cerrado, sendo uma delas realizada em parceria com Embrapa Cerrado, intitulada "Receitas com araticum sabor e aroma em equilíbrio perfeito", e outras duas realizadas durante a visita a uma propriedade rural.

Essa etapa de treinamento alcançou 299 participantes registrados. Essas oficinas proporcionarão às famílias dos pequenos produtores rurais subsídios para a difusão de técnicas de fabricação dos produtos de maior interesse, além de divulgar e avaliar novas preparações. Durante essa capacitação, foram considerados aspectos relacionados às normas sanitárias e de qualidade, mantendo, ao mesmo tempo, as características artesanais desejadas 
pelos consumidores. Durante a fase de treinamento, foram distribuídos folders e cartilhas educativas para serem utilizados nas atividades de capacitação e distribuídos à população.

Com relação à capacitação e conscientização de produtores rurais para a preservação e aproveitamento do marolo nas propriedades, foi realizado um dia de campo com 75 participantes, entre produtores rurais, docentes e discentes da Unifal-MG e de outras instituições de ensino. Está prevista ainda a implantação de UDs de plantio consorciado de marolo com café e com pastagem. A produção de 2.000 mudas para essas unidades e para distribuição aos produtores rurais está sendo feita em conjunto com a Prefeitura Municipal de Três Pontas. A implantação das UDs foi viabilizada por meio de convênio da EMATER-MG com o Instituto Estadual de Florestas (IEF) e deverá ocorrer a partir de 2010.

\section{CONSIDERAÇÕES FINAIS}

O presente artigo teve como objetivo relatar as atividades desenvolvidas e resultados obtidos dos trabalhos de pesquisa e extensão com o marolo, desenvolvidos na Universidade Federal de Alfenas (UNIFAL-MG) em parceria com a Empresa de Assistência Técnica e Extensão Rural de Minas Gerais (EMATER-MG) e outras instituições.

Essas atividades permitiram principalmente a sensibilização e mobilização da comunidade e sociedade para os problemas envolvidos na produção e comercialização do marolo. Essa mobilização fez com que outras atividades começassem a ser desenvolvidas, como, por exemplo, a Festa do Marolo, que passará a ser realizada pela Prefeitura Municipal de Paraguaçu, desencadeando ações que ultrapassam os limites iniciais propostos pelo projeto.

O treinamento das técnicas de bem-estar social da EMATER-MG, de pequenos agricultores e produtores artesanais está permitindo também a geração de trabalho e renda em comunidades que vão além da microrregião de Alfenas/MG. Dessa forma, as atividades desenvolvidas possibilitaram a efetiva transferência de tecnologia e conhecimento entre a comunidade do cerrado, acadêmicos, docentes, EMATER-MG.

As atividades multidisciplinares fomentaram a atuação conjunta entre os envolvidos no projeto, possibilitando a continuidade da proposta e a articulação de novas parcerias. Pretende-se contribuir, não somente com a renda e a alimentação de muitas famílias, mas também assegurar o desenvolvimento sustentável dessas comunidades, protegendo o cerrado e seus recursos naturais. 


\section{AGRADECIMENTOS}

A Unifal-MG e Emater-MG pela oportunidade de condução do projeto; ao PROBIC II/UNIFAL e CNPq por concessão de bolsas de iniciação científica; a FAPEMIG (CAG APQ-02130-08) e PROEXT/MEC/SESU pelo suporte financeiro.

\section{REFERÊNCIAS}

IBGE (a) Produto Interno Bruto do Municípios 2003-2007. Instituto Brasileiro de Geografia e Estatística. Disponível em: < http://www.ibge.gov.br/home/estatistica/economia/pibmunicipios/2003_2007/default.shtm>. Acesso em 11 mar. 2010.

IBGE (b) Contagem da população 2007. Instituto Brasileiro de Geografia e Estatística. Disponível em:

http://www.ibge.gov.br/home/estatistica/populacao/contagem2007/default.shtm. Acesso em 23 fev. 2010.

NOGUEIRA, E. et. al. Produção e Comercialização de Anonáceas em São Paulo e Brasil. Informações Econômicas, São Paulo, v. 35, n._2, 2005.

OLIVEIRA, M. A. M. de; POLO, et al. AVALIAÇÃO SENSORIAL DOS PRODUTOS ELABORADOS A PARTIR DA POLPA DO MAROLO (Annona crassiflora Mart.). In: I Simpósio do Marolo e Frutos do Cerrado. Anais..., Alfenas, 2009.

POLO, M.; et al. Biometria do Fruto e Formas de Produção e Comercialização do Marolo ( Annona Crassiflora) na Microregião de Alfenas_MG. In: 59 Congresso Nacional de Botânica, Anais..., Natal, 2008.

ROESLER, R. et al. Evaluation of the Antioxidant Properties of the Brazilian Cerrado Fruit Annona crassiflora (Araticum). Journal of Food Science. 71, 103-107, 2006

ROESLER, R. et al. Antioxidant activity of Annona crassiflora: Characterization of major components by electrospray ionization mass spectrometry. Food Chemistry. 104, 1048-1054, 2007.

ROSA, J. G. Grande sertão: veredas. São Paulo: Nova Fronteira, 2006.

VILAR, J. B. et al. Assessment of the mutagenic, antimutagenic and cytotoxic activities of ethanolic extract of araticum (Annona crassiflora Mart. 1841) by micronucleus test in mice. Braz. J. Biol. 68, 141-147, 2008

VILAS BOAS, E. V. de B.; SILVA, E. P. Maturação controlada de marolo: um caso a ser estudado. In: I Simpósio do Marolo e Frutos do Cerrado. Anais..., Alfenas, 2009. 